Article

\title{
Prediction of Vehicle Crashworthiness Parameters Using Piecewise Lumped Parameters and Finite Element Models
}

\author{
Bernard B. Munyazikwiye ${ }^{1,2, *(0)}$, Dmitry Vysochinskiy ${ }^{1}\left(\mathbb{D}\right.$, Mikhail Khadyko $^{3}{ }^{(1)}$ and \\ Kjell G. Robbersmyr ${ }^{1}$ [D \\ 1 Department of Engineering Sciences, University of Agder, Jon Lilletuns Vei 9, 4879 Grimstad, Norway; \\ dmitry.vysochinskiy@uia.no (D.V.); kjell.g.robbersmyr@uia.no (K.G.R.) \\ 2 Department of Mechanical and Energy Engineering, College of Science and Technology, University of \\ Rwanda, Avenue de l'Armée, P.O.Box 3900 Kigali, Rwanda \\ 3 Department of Structural Engineering, Norwegian University of Science and Technology, Richard Birkelands \\ Vei 1A, 7491 Trondheim, Norway; mikhail.khadyko@ntnu.no \\ * Correspondence: bernard.munyazikwiye@uia.no; Tel.: +250-788-842-534
}

Received: 31 August 2018; Accepted: 23 October 2018; Published: 30 October 2018

\begin{abstract}
Estimating the vehicle crashworthiness experimentally is expensive and time-consuming. For these reasons, different modelling approaches are utilised to predict the vehicle behaviour and reduce the need for full-scale crash testing. The earlier numerical methods used for vehicle crashworthiness analysis were based on the use of lumped parameters models (LPM), a combination of masses and nonlinear springs interconnected in various configurations. Nowadays, the explicit nonlinear finite element analysis (FEA) is probably the most widely recognised modelling technique. Although informative, finite element models (FEM) of vehicle crash are expensive both in terms of man-hours put into assembling the model and related computational costs. A simpler analytical tool for preliminary analysis of vehicle crashworthiness could greatly assist the modelling and save time. In this paper, the authors investigate whether a simple piecewise LPM can serve as such a tool. The model is first calibrated at an impact velocity of $56 \mathrm{~km} / \mathrm{h}$. After the calibration, the LPM is applied to a range of velocities $(40,48,64$ and $72 \mathrm{~km} / \mathrm{h})$ and the crashworthiness parameters such as the acceleration severity index (ASI) and the maximum dynamic crush are calculated. The predictions for crashworthiness parameters from the LPM are then compared with the same predictions from the FEA.
\end{abstract}

Keywords: piecewise lumped parameters; finite element analysis; dynamic crush; acceleration severity index

\section{Introduction}

Car accidents are among the major causes of mortality in modern society. In the automotive industry, safety is one of the main design considerations. When there is a progressive collapse of the vehicle structure during a frontal crash, two basic requirements should be fulfilled for preventing death or serious injury to the occupants. The first requirement ensures that occupants do not sustain injuries caused by high inertia forces. It dictates that the parameters that characterise the inertia forces felt by the occupant are kept below the threshold values specified in the corresponding standards.

According to the European Standard EN1317-1 [1], a measure of potential injury due to inertia forces during a crash event is the acceleration severity index (ASI), which is calculated from the acceleration measurement at the centre of gravity of the car. The second requirement ensures that occupants are not clamped by the car structure during the crash event. To fulfil this requirement, 
the deformation of the passenger compartment needs to be limited. The severity of car deformation can be estimated by maximum dynamic crush, which is the maximum displacement of the car front with respect to its centre of gravity [2].

Usually, full-scale crash tests (FSCT) are performed to ensure the safe range of risk. Prior to the development of powerful computers, up until the early 1970s, crash studies relied almost exclusively on experimental full-scale testing. However, FSCT is expensive, time-consuming and requires sophisticated infrastructure and highly qualified personnel. Therefore, numerical modelling and simulation are actively used to study and analyse car crashes. Simulation of vehicle crashworthiness has been evolving over the past 45 years. The earlier numerical methods used for vehicle crashworthiness were based on the use of the lumped masses and nonlinear springs. The models built with these methods, known as lumped parameters models (LPM), used lumped masses to represent parts of the vehicle, such as engine block and the passenger compartment, considered rigid during the analysis, and the springs to represent the structural elements responsible for absorbing the kinetic energy.

Various examples of the use of LPM to vehicle crash reconstruction and evaluation of vehicle crashworthiness can be found in the literature. One of the earliest and successful examples of the use of LPM is the model developed by Kamal in 1970s for simulation of vehicle frontal crash at velocities between 0 and $30 \mathrm{mph}(48 \mathrm{~km} / \mathrm{h})$ [3]. The model was a 3-degrees of freedom (DOF) system composed of three masses and eight springs. In the past few decades, much research has been carried out in the field of vehicle crashworthiness using LPM which resulted in several novel computational models of vehicle collisions. In [4], Marzbanrand expanded the Kamal model to a 5-DOF LPM for the frontal crash and analysed the response of occupant during the impact. Meler et al. [5] performed a system identification for a vehicle frontal crash using a multi-objective optimisation approach. The front end of the vehicle was modelled as a 3 DOF system composed by the passenger compartment; the front wheels, cross-member, and suspension system; and engine interconnected by springs. Kim et al. [6] developed simple approaches for optimising vehicle structure crashworthiness using a single mass-spring-damper system. Huang [7] developed several mathematical models for vehicle crashworthiness using the LPM approach. Inspired by Huang 's work, Pawlus et al. [2,8] presented results for vehicle crashworthiness assessment using a single mass-spring-damper system. In [9], the authors proposed an approach to control the seat belt restraint system force during a frontal crash to reduce thoracic injury. Klausen et al. $[10,11]$ introduced a firefly optimisation method to estimate parameters of vehicle crash test based on a single mass-spring-damper model. Ofochebe et al. [12] studied the performance of a vehicle front structure using a 5-DOF lumped mass-spring model composed of body, engine, the cross-member, the suspension, and the bumper masses. Munyazikwiye et al. [13,14] applied piecewise linear lumped parameters models and a genetic algorithm (GA) to simulate a vehicle impact (accommodating an occupant) into the barrier and a vehicle-to-vehicle frontal crash, respectively. This GA was also used in [15] for calculating the optimised parameters of a 12-DOF model for two vehicle types in two different frontal crashes.

Lim [16,17], using SISAME software, presented various research results based on the extraction of lumped parameters from the experimental data to reconstruct the vehicle crash kinematics. In addition, Mentzer et al. [18,19] presented the essential formulation of SISAME for extracting the LPM from crash test. Gabler et al. [20] developed LPMs for vehicle into barrier and vehicle-to-vehicle crashes using the SISAME code to extract the model parameters. Recently, Mazurkiewicz et al. [21] used the LPM to improve the safety of children transported in motor vehicles subjected to a side impact during a vehicle crash. Vangi et al. [22] proposed a step-by-step procedure to collect data for a two vehicles accident reconstruction. In [23-26], the authors proposed an optimisation procedure to assist multi-body vehicle model development for vehicle crashworthiness. Tso-Liang et al. [24] examined the dynamic response of a human body in a crash event and assessed the injuries sustained to the occupant's head, chest and pelvic regions. 
Even though LPMs have shown useful results in terms of crash reconstruction, some of their limitations have been pointed out in literature. The major challenge of the LPM for vehicle crash analysis is the dependency of LPM on the availability of calibration data. That is, the spring characteristics of the system are determined from existing data, either from a full-scale crash test or from a finite element model $[27,28]$. A previous work, on a similar study, concluded that LPMs are valid only for data which are used for their creation and could not be simulated for different velocities [2]. This left an open question which needed to be addressed.

The other commonly used approach for vehicle crash analysis is the Finite Element Analysis (FEA). Among the various vehicle crash simulation techniques, explicit FEA is probably the most frequently used and it has been used to calibrate the LPM effectively. Deb and Srinivas in [29] calibrated an LPM for vehicle side impact based on data from an FEM. In [30], the authors developed an LPM of crash energy absorbing structure for frontal crash. The stiffness characteristics of the structure was obtained from the result of an FEM. Ofochebe et al. [31] developed an absorbable energy monitoring scheme for testing the vehicle structural crashworthiness by calibrating an LPM to an equivalent front-half FEM of a vehicle. Tanlak et al. [32] calibrated an LPM from an FEA of a bumper beam subjected to high impact velocity. However, finite element models have some limitations: They are relatively complex and require a large amount of computational time.

Although out-shined by the more sophisticated finite element modelling techniques, simple lumped parameters models are still used today, especially when it comes to reconstruction of the crash event. The availability of a simpler numerical tool for estimation of basic vehicle crashworthiness parameters can assist the designer and speed up the design process. LPM might serve as such a tool.

Although LPMs have been extensively used for reconstruction of crash scenario at specific impact velocity, it is still worthy to explore more the use of LPM, for predicting the crash event at various impact velocities as a complement to the existing results e.g., in $[11,33,34]$. In this paper, the authors investigate whether it is possible to accurately estimate the basic crashworthiness parameters such as maximum dynamic crush and ASI, using the earlier proposed LPM [13,14]. The piecewise linear LPM is calibrated to the acceleration signal from FSCT and from FEM. Then, the model prediction capability is validated by comparing its predictions with those from an FEA at different impact velocities.

\section{Materials and Methods}

A full-scale crash test of a Ford Taurus (2004 model) in Figure 1 is chosen as a baseline for the LPM and FEA used in this paper. The test weight and impact speed of the vehicle were $1739 \mathrm{~kg}$ and $56 \mathrm{~km} / \mathrm{h}$, respectively. The acceleration signal and the finite element analysis model inputs used in this study were obtained from an NHTSA open database [35,36].

The processing of the acceleration signal, calculation of ASI and maximum dynamic crush; and the FEA were done by the authors.

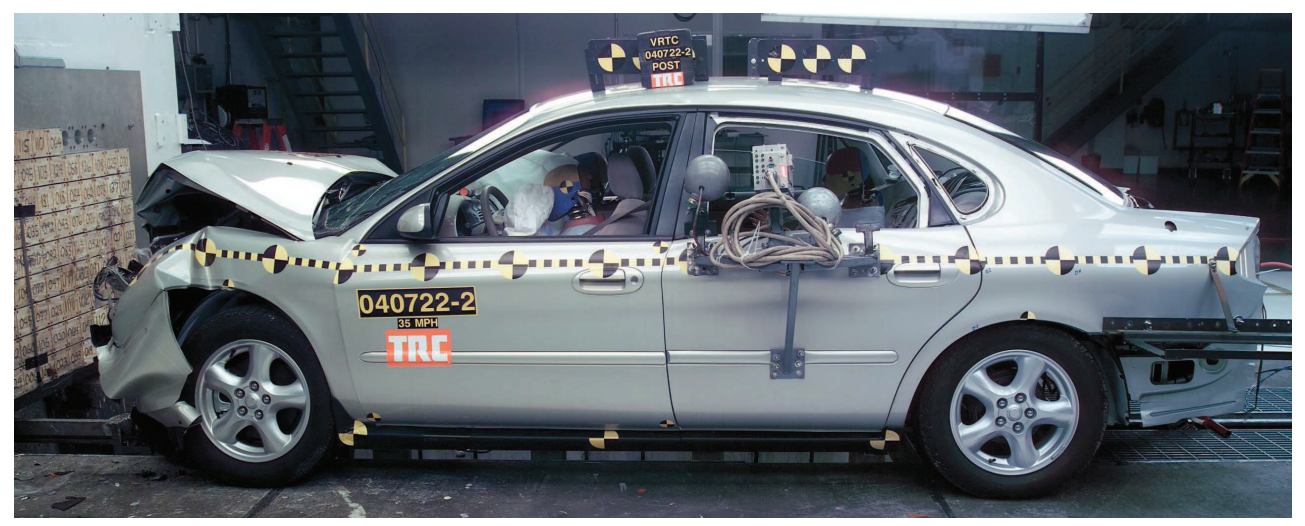

Figure 1. Full-scale crash test of a Ford Taurus (2004 model) at 56 km/h [35]. 


\subsection{Experimental Data and Signal Filtering}

In this paper, the acceleration signal is first filtered using a Finite Impulse Response (FIR) filter before performing a numerical integration to obtain the velocity and displacement responses, respectively. Figure 2 shows the noisy and filtered acceleration signals for a vehicle crashing into a barrier. A cut-off frequency of $0.5 \mathrm{kHz}$ with a sampling rate of $10 \mathrm{kHz}$ is chosen while designing a suitable low pass filter. A filter order of 30 and a Kaiser window are used for filtering the acceleration signal.

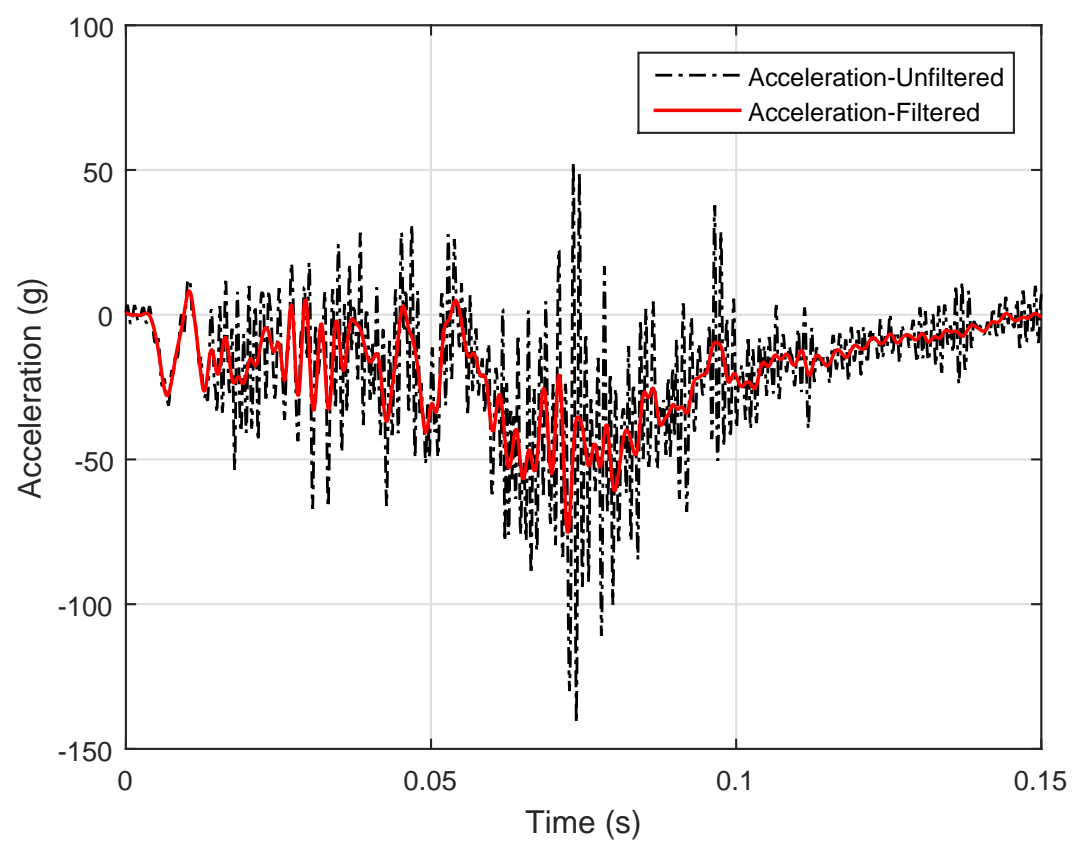

Figure 2. Noisy and filtered acceleration signals for full-scale frontal crash [35].

\subsection{Piecewise Linear Lumped Parameters Model}

The model consists of a Kelvin model shown in Figure 3. The mathematical expression of the model is a normal second order differential equation as shown in the following:

$$
\ddot{x}=\left(-F_{k}-F_{c}\right) / m,
$$

where $\dot{x}$ and $x$ are the velocity and displacement of the centre of gravity of mass $m$ (the mass of the vehicle); and $F_{k}, F_{c}$ are the built-up spring and damping forces defined in the following equations:

$$
\begin{aligned}
& F_{k}=k(x) \cdot x, \\
& F_{c}=c(\dot{x}) \cdot \dot{x} .
\end{aligned}
$$

Equation (1) is solved using a numerical integration to get the model velocity and displacement time-histories, respectively and are then expressed as

$$
\begin{aligned}
& \dot{x}(i+1)=\dot{x}(i)+\ddot{x}(i) \Delta t, \\
& x(i+1)=x(i)+\dot{x}(i) \Delta t,
\end{aligned}
$$

with $i=1$ :(length $(t)-1), t$ is the time vector and $\Delta t$ is a time step. 


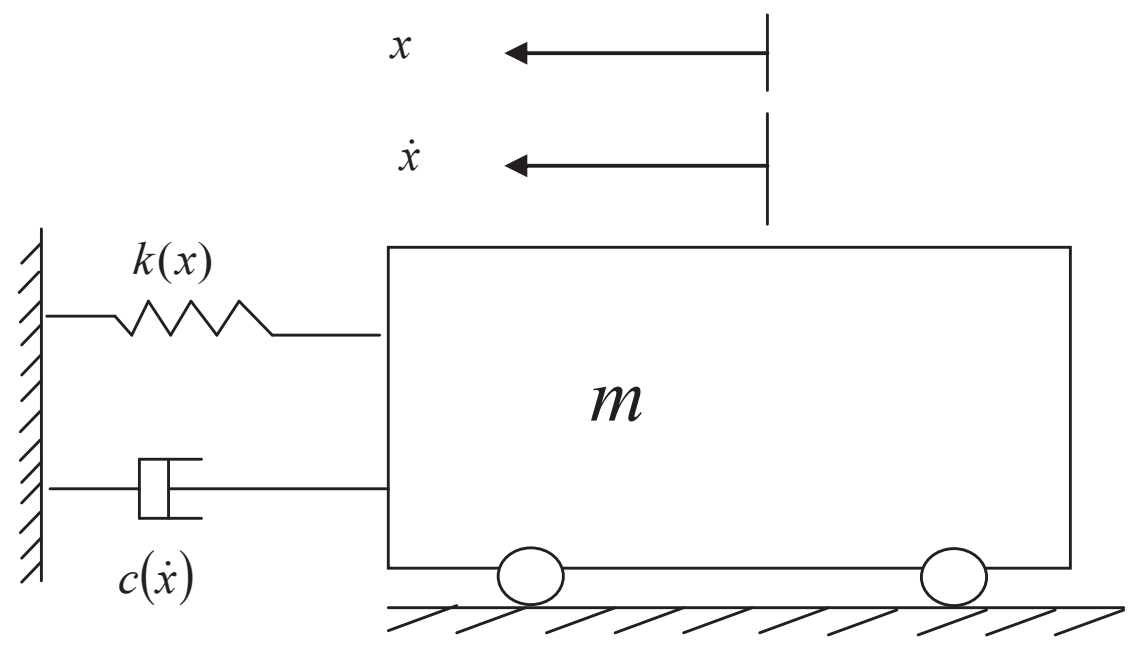

Figure 3. Lumped parameter model.

The spring stiffness and damping coefficients in the model, are defined as the piecewise linear functions of $x$ and $\dot{x}$, respectively. These functions are

$$
\begin{gathered}
k(x)= \begin{cases}k_{1}+\frac{k_{2}-k_{1}}{x_{1}} x & 0 \leq x \leq x_{1}, \\
k_{2}+\frac{k_{3}-k_{2}}{x_{2}-x_{1}}\left(x-x_{1}\right) & x_{1} \leq x \leq x_{2}, \\
k_{3}+\frac{k_{4}-k_{3}}{C_{m}-x_{2}}\left(x-x_{2}\right) & x_{2} \leq x \leq C_{m},\end{cases} \\
c(\dot{x})= \begin{cases}c_{1}-\frac{c_{1}-c_{2}}{\dot{x}_{1}} \dot{x} & 0 \leq \dot{x} \leq \dot{x}_{1}, \\
c_{2}-\frac{c_{2}-c_{3}}{\dot{x}_{2}-\dot{x}_{1}}\left(\dot{x}-\dot{x}_{1}\right) & \dot{x}_{1} \leq \dot{x} \leq \dot{x}_{2}, \\
c_{3}-\frac{c_{3}-c_{4}}{v_{0}-\dot{x}_{2}}\left(\dot{x}-\dot{x}_{2}\right) & \dot{x}_{2} \leq \dot{x} \leq v_{0},\end{cases}
\end{gathered}
$$

where the upper limits $C_{m}$ and $v_{0}$ are the maximum dynamic crush and initial velocity from the FSCT or FEM used for calibration of the LPM at $v_{0}=56 \mathrm{~km} / \mathrm{h}$. Equations (5a) and (5b) were used to calibrate the LPM. The intention was to reconstruct the crash event by simplest LPM possible and the model with three intervals was shown to be accurate enough during the earlier studies $[13,14]$. The prediction is performed by excluding the lower and upper limits in Equation (5) and subjecting the calibrated LPM to different impact velocities. Then, the piecewise linear functions are

$$
\begin{gathered}
k(x)= \begin{cases}k_{1}+\frac{k_{2}-k_{1}}{x_{1}} x & x \leq x_{1}, \\
k_{2}+\frac{k_{3}-k_{2}}{x_{2}-x_{1}}\left(x-x_{1}\right) & x_{1} \leq x \leq x_{2}, \\
k_{3}+\frac{k_{4}-k_{3}}{C_{m}-x_{2}}\left(x-x_{2}\right) & x \geq x_{2},\end{cases} \\
c(\dot{x})= \begin{cases}c_{1}-\frac{c_{1}-c_{2}}{\dot{x}_{1}} \dot{x} & \dot{x} \leq \dot{x}_{1}, \\
c_{2}-\frac{c_{2}-c_{3}}{\dot{x}_{2}-\dot{x}_{1}}\left(\dot{x}-\dot{x}_{1}\right) & \dot{x}_{1} \leq \dot{x} \leq \dot{x}_{2}, \\
c_{3}-\frac{c_{3}-c_{4}}{v_{0}-\dot{x}_{2}}\left(\dot{x}-\dot{x}_{2}\right) & \dot{x} \geq \dot{x}_{2} .\end{cases}
\end{gathered}
$$




\subsection{LPM Estimation and Calibration Scheme Using the Genetic Algorithm}

The procedure for solving the problem defined in Equation (1) is shown in Figure 4. The genetic algorithm (GA) attempts to move points through a series of generations, each being composed of a population which has a set number (population size, 200 in this work) and 12 parameters (four stiffness values, four damping coefficient values, two position values, $x_{1}$ and $x_{2}$, two intermediate velocities $\dot{x}_{1}$ and $\dot{x}_{2}$ ).

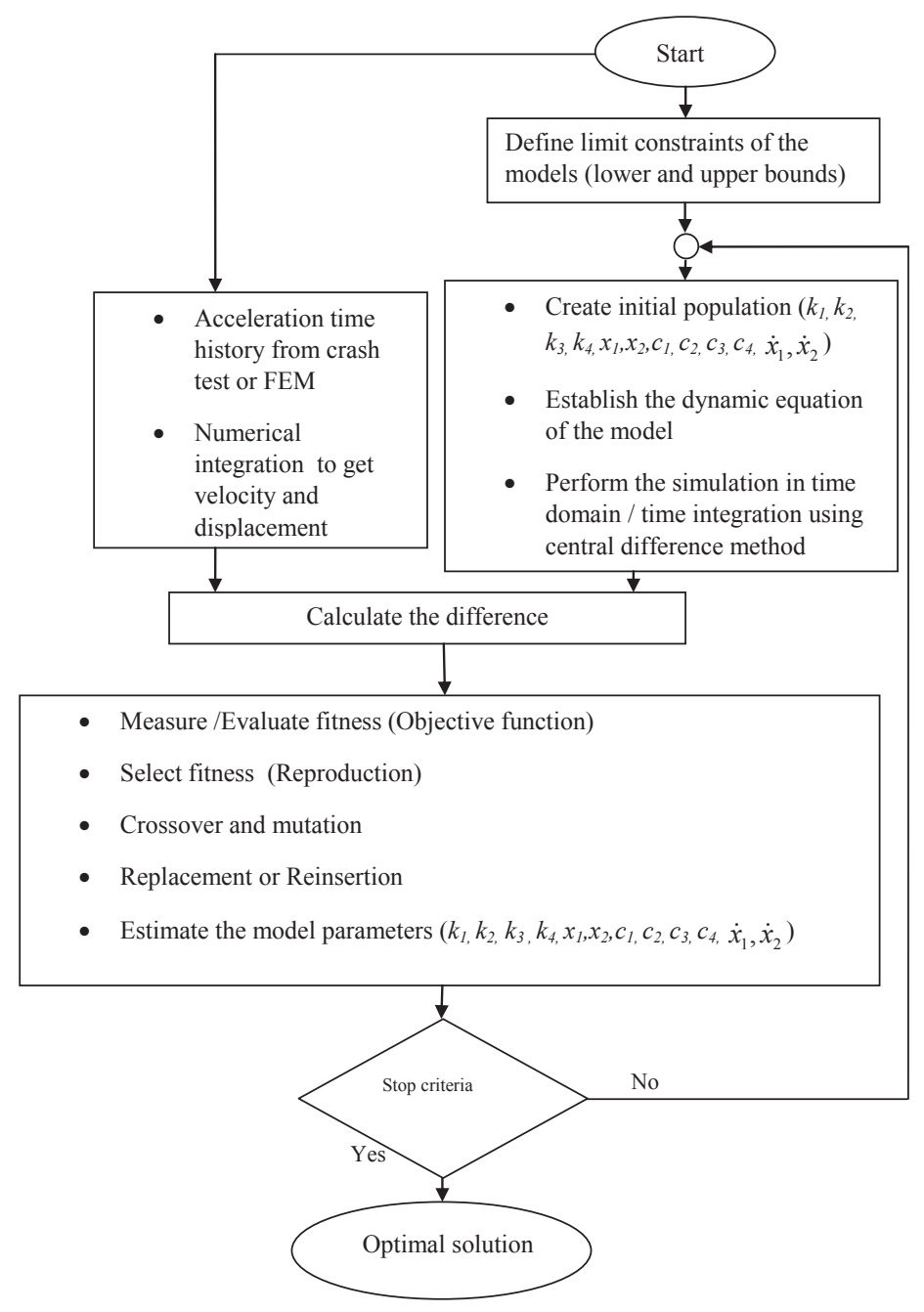

Figure 4. Calibration procedure using genetic algorithm.

The proposed algorithm seeks to find the minimum of an objective function as can be stated in a general form $\min f(p)$, where $p$ denotes the unknown variables in the model. In this paper, the two objective functions to be minimised are the error functions $E_{1}(p, t)$ and $E_{2}(p, t)$ between the acceleration time-history obtained from the LPM and the calibration data. From the estimated acceleration, the displacement and velocity time-histories are thereafter derived by numerical integration. The objective functions are defined in Equations (7a) and (7b):

$$
\begin{gathered}
E_{1}(p, t)=\sum_{i=1}^{N} \sqrt{\left[a_{F S C T}\left(t_{i}\right)-a_{L P M}\left(p, t_{i}\right)\right]^{T} \times a_{F S C T}\left(t_{i}\right)-a_{L P M}\left(p, t_{i}\right)}, \\
E_{2}(p, t)=\sum_{i=1}^{N} \sqrt{\left[a_{F E A}\left(t_{i}\right)-a_{L P M}\left(p, t_{i}\right)\right]^{T} \times a_{F E A}\left(t_{i}\right)-a_{L P M}\left(p, t_{i}\right)},
\end{gathered}
$$


where $a_{F S C T}, a_{L P M}$ and $a_{F E A}$ are accelerations from the FSCT, LPM and FEA, respectively and $N$ is the number of data points. An initial guess of parameters is chosen and substituted in the piecewise linear functions defined in Equations (5a) and (5b). The obtained spring stiffness and damping coefficients are substituted into Equations (2a) and (2b), which are respectively substituted in the dynamic Equation (1). Then, Equation (1) is solved numerically to get the simulated kinematic results. Finally, these kinematic results are compared with the calibration data. The objective functions in Equations (7a) and (7b) are evaluated, and when the stop criterion is met the solver terminates; otherwise, the GA keeps on tuning the model parameters until the LPM results match the calibration data (experimental or FEA results).

\subsection{Finite Element Analysis}

As mentioned earlier, the input to finite element analysis was obtained from the National Highway Traffic Safety and Administration (NHTSA) open database [36]. The following is a summary describing the studied FEM:

- Number of parts: 804,

- Number of nodes: 922,007,

- Number of beam elements: 10 ,

- Number of shell elements: 838,926 ,

- $\quad$ Number of solid elements: 134,468 .

The simulations were performed using the LS-DYNA software Version R8.10 (Revision R8.105896) developed by Livermore Software Technology Corporation (LSTC), Livermore, CA, USA. The impact velocities of $40,48,56,64$, and $72 \mathrm{~km} / \mathrm{h}$ were simulated. An acceleration signal was recorded at the centre of gravity (CG) of the finite element model.

In the case when the finite element analysis uses the under-integrated shell and solid elements, non-physical, zero-energy deformation modes such as hourglass modes might occur. Some small amount of hourglass energy can be tolerated, but this non-physical deformation mode needs to be kept under control. The ratio of the hourglass energy to the internal energy should not exceed the recommended value. In the presented analysis, this ratio was carefully controlled and kept below $10 \%$ of the peak internal energy, which is the recommended value according to [37,38]. The ratio of hourglass energy to the highest internal energy was 0.078 . The actual computation time for a single crash simulation supported by the LS-DYNA was between one and two days.

\subsection{Acceleration Severity Index (ASI)}

The ASI is intended to give a measure of the severity of inertia force experienced by a person seated in the proximity of the CG of the vehicle during impact. The ASI is derived from the acceleration time-histories measured at the CG of the impacting vehicle and is computed as follows [39]:

$$
\operatorname{ASI}\left(t_{i}\right)=\sqrt{\left(\frac{\bar{a}_{x}}{\hat{a}_{x}}\right)^{2}+\left(\frac{\bar{a}_{y}}{\hat{a}_{y}}\right)^{2}+\left(\frac{\bar{a}_{z}}{\hat{a}_{z}}\right)^{2}},
$$

where $\hat{a}_{x}=12 g, \hat{a}_{y}=9 g, \hat{a}_{z}=10 g$ are limit values for the components of the acceleration along the body axes $x$ (longitudinal direction), $y$ (lateral direction) and $z$ (vertical direction), respectively. These values are obtained from the human body tolerance limits, interpreted as the values below which passenger risk is very small (light injury if any) and $g=9.81 \mathrm{~m} / \mathrm{s}^{2}$ is the acceleration due to gravity, while $\bar{a}_{x}$, $\bar{a}_{y}, \bar{a}_{z}$ are the components of acceleration of a selected point at the CG of the vehicle, averaged over 
a moving time interval $\delta=0.050$ seconds and the ASI is the maximum value of ASI(t). The average acceleration components are defined in Equation (9):

$$
\begin{aligned}
& \bar{a}_{x}=\frac{1}{\delta} \int_{t}^{t+\delta} a_{x} d t \\
& \bar{a}_{y}=\frac{1}{\delta} \int_{t}^{t+\delta} a_{y} d t, \\
& \bar{a}_{z}=\frac{1}{\delta} \int_{t}^{t+\delta} a_{z} d t .
\end{aligned}
$$

In case of a full frontal crash, the acceleration components in the lateral and vertical directions are less significant as compared to the longitudinal acceleration. Hence, in this work, the computation of ASI involves only the longitudinal component and its associated $12 g$ threshold acceleration. That is:

$$
A S I=\frac{\left|\bar{a}_{x}\right|}{12 g} .
$$

In case of collision with a rigid barrier, all the impact energy is absorbed by the vehicle structure. Thus, the European standard EN 1317-2:2010 [39] does not specify any standard values of ASI on impact with the rigid barriers. For reference, the prescribed values of ASI for flexible barriers are:

- Class A: ASI $\leq 1$,

- Class B: $1.0 \leq \mathrm{ASI} \leq 1.4$,

- $\quad$ Class C: $1.4 \leq \mathrm{ASI} \leq 1.9$.

The impact Severity Class A indicates a greater level of safety for vehicle occupants than Class B and the same for class B compared to class C. The more the ASI exceeds unity, the more the impact consequences for the passengers are dangerous [40].

\section{Results}

The spring stiffness and damping coefficient characteristics of the vehicle's front structure, optimised through the GA, are shown in Table 1.

Table 1. Estimated structural parameters of the vehicle frontal crash model calibrated at $56 \mathrm{~km} / \mathrm{h}$.

\begin{tabular}{ccc}
\hline Parameters & LPM Calibrated to FSCT & LPM Calibrated to FEM \\
\hline$k_{1}$ & $7195 \mathrm{~N} / \mathrm{m}$ & $25,718 \mathrm{~N} / \mathrm{m}$ \\
$k_{2}$ & $7210 \mathrm{~N} / \mathrm{m}$ & $31,444 \mathrm{~N} / \mathrm{m}$ \\
$k_{3}$ & $25,386 \mathrm{~N} / \mathrm{m}$ & $45,476 \mathrm{~N} / \mathrm{m}$ \\
$k_{4}$ & $711,060 \mathrm{~N} / \mathrm{m}$ & $467,830 \mathrm{~N} / \mathrm{m}$ \\
$x_{1}$ & $0.0526 \mathrm{~m}$ & $0.2448 \mathrm{~m}$ \\
$x_{2}$ & $0.1023 \mathrm{~m}$ & $0.2923 \mathrm{~m}$ \\
$c_{1}$ & $59,444 \mathrm{Ns} / \mathrm{m}$ & $80,827 \mathrm{Ns} / \mathrm{m}$ \\
$c_{2}$ & $51,590 \mathrm{Ns} / \mathrm{m}$ & $7775 \mathrm{Ns} / \mathrm{m}$ \\
$c_{3}$ & $4997 \mathrm{Ns} / \mathrm{m}$ & $38,812 \mathrm{Ns} / \mathrm{m}$ \\
$c_{4}$ & $1382 \mathrm{Ns} / \mathrm{m}$ & $5703 \mathrm{Ns} / \mathrm{m}$ \\
$\dot{x}_{1}$ & $7.0585 \mathrm{~m} / \mathrm{s}$ & $4.7855 \mathrm{~m} / \mathrm{s}$ \\
$\dot{x}_{2}$ & $8.9272 \mathrm{~m} / \mathrm{s}$ & $8.2880 \mathrm{~m} / \mathrm{s}$
\end{tabular}

LPM: Lumped Parameters Model, FSCT: Full-Scale Crash Test, FEM: Finite Element Model.

Figure 5 illustrates three out of five FEA simulations of a Ford-Taurus (2004 model) crashing into a fixed rigid wall at initial velocities of 40,56 , and $72 \mathrm{~km} / \mathrm{h}$, respectively. The convergences of the objective functions are satisfied since their fitness values are constant across a large number of generations as shown in Figure 6. 


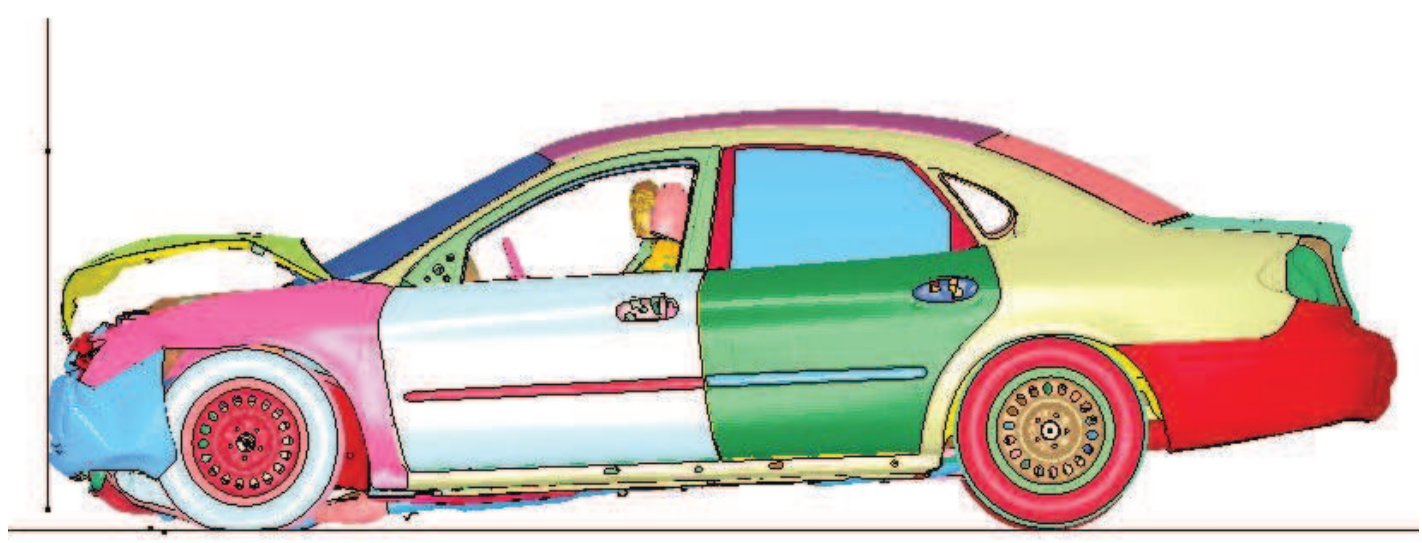

(a)

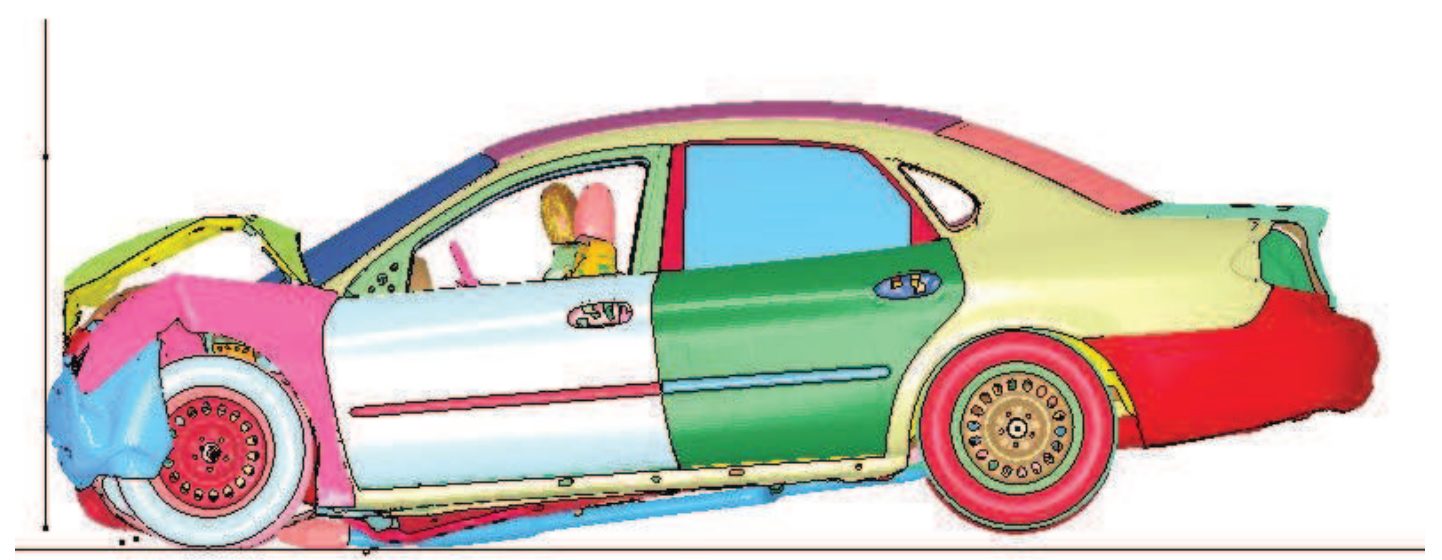

(b)

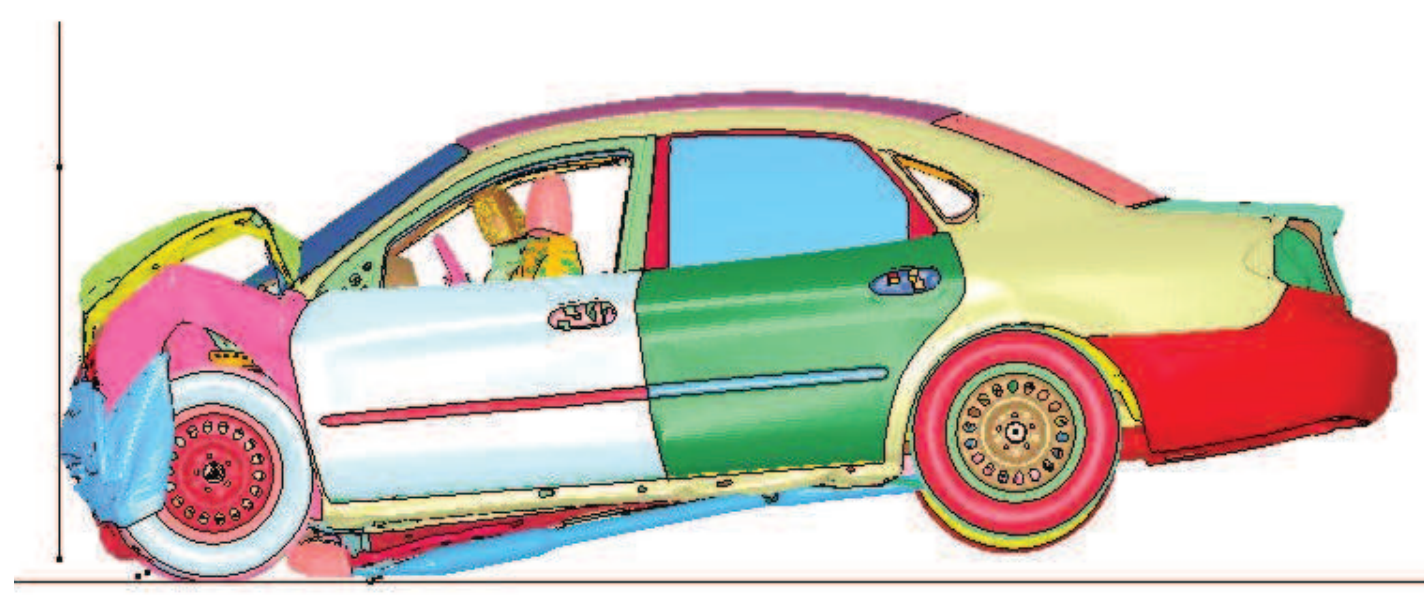

(c)

Figure 5. Deformed vehicle frontal structure through finite element analysis at impact velocities of (a) $40 \mathrm{~km} / \mathrm{h}$; (b) $56 \mathrm{~km} / \mathrm{h}$; and (c) $72 \mathrm{~km} / \mathrm{h}$.

The kinematic time-history (displacements, velocities, and accelerations) are compared as shown in Figures 7 and 8. These Figures show the predictions of the LPM for a range of velocities (40, 48, 56,64 , and $72 \mathrm{~km} / \mathrm{h}$, respectively). Figure 9 presents a summary of kinematics results of the LPM calibrated at $56 \mathrm{~km} / \mathrm{h}$ against the FSCT and FEA, respectively. 
The crashworthiness parameters in terms of maximum dynamic crush $\left(C_{m}\right)$, time of crush $\left(t_{m}\right)$ and ASI for the range of velocities are summarised in Table 2.

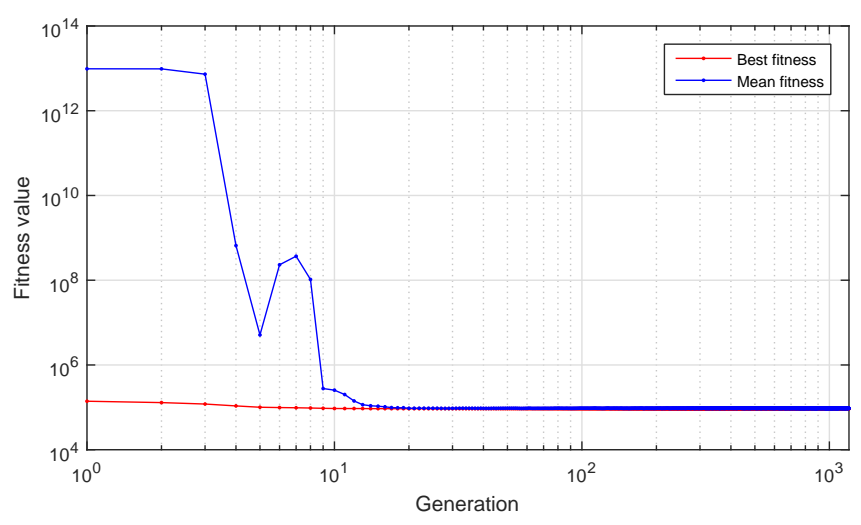

(a)

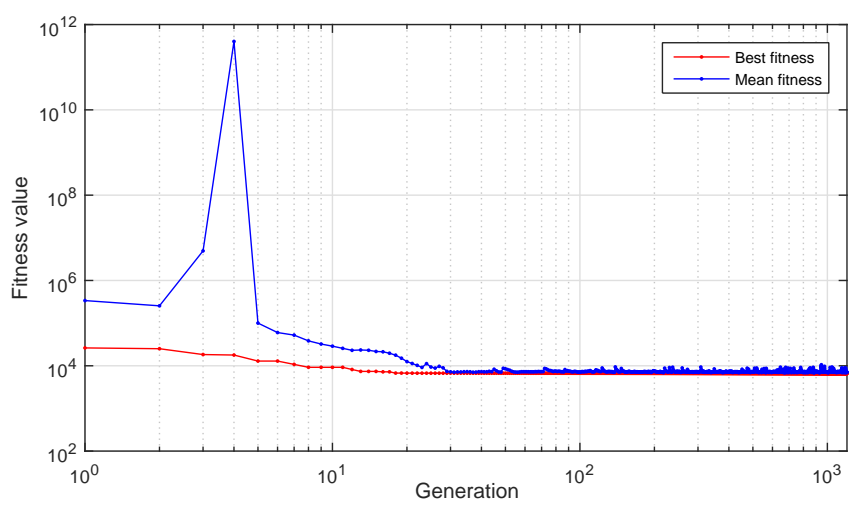

(b)

Figure 6. Convergence of the objective function using genetic algorithm (a) Lumped parameters model calibrated to full-scale crash test; (b) Lumped parameters model calibrated to finite element model.

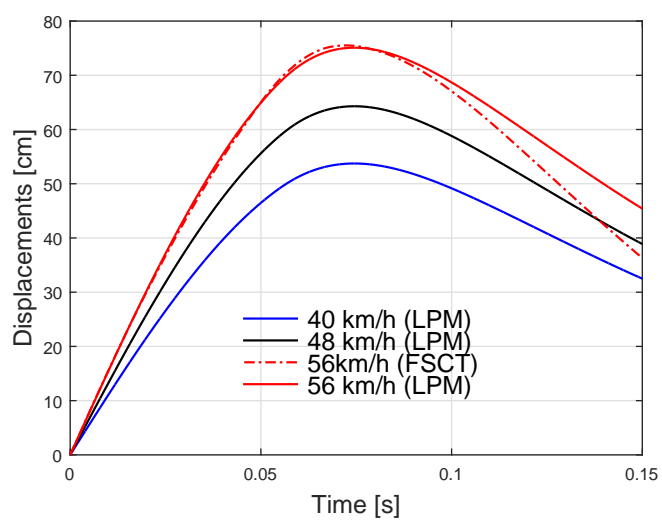

(a)

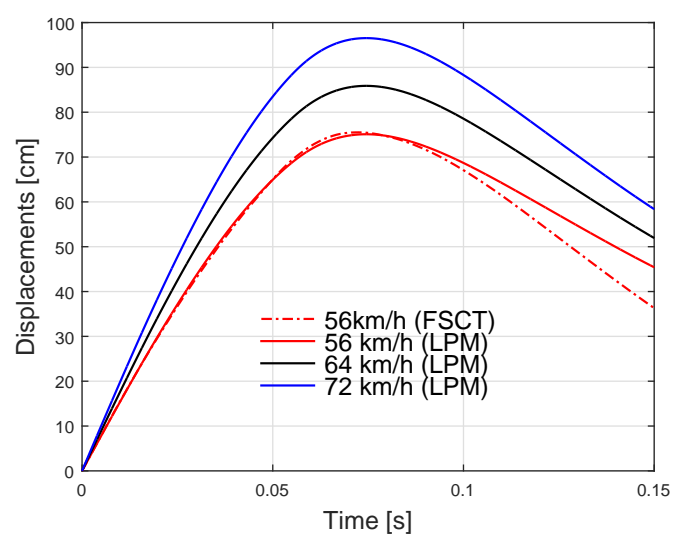

(b)

Figure 7. Cont. 


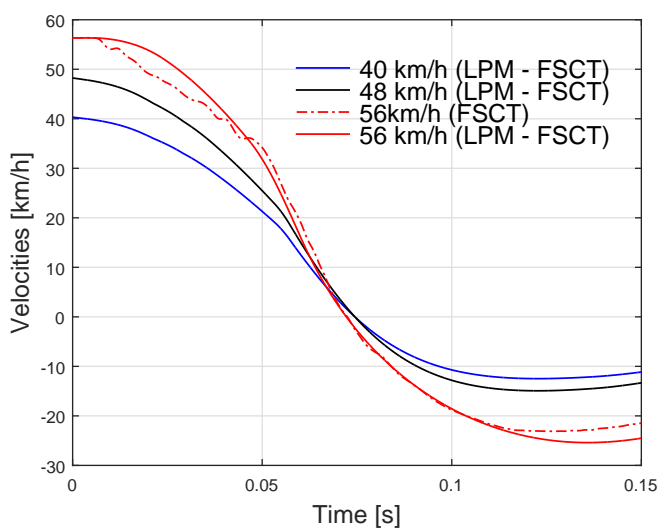

(c)

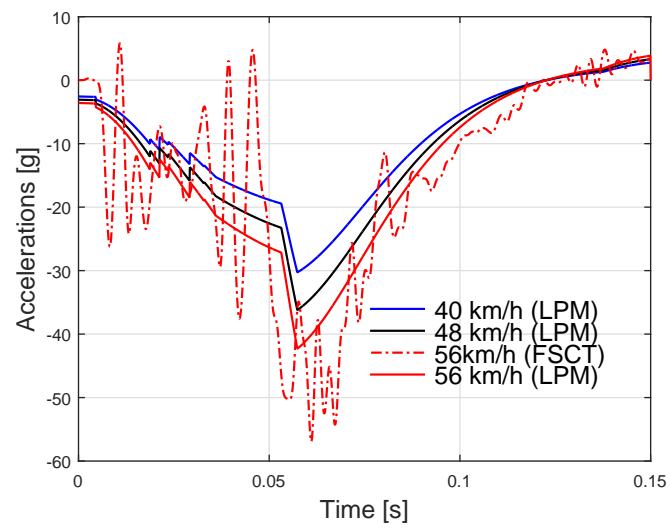

(e)

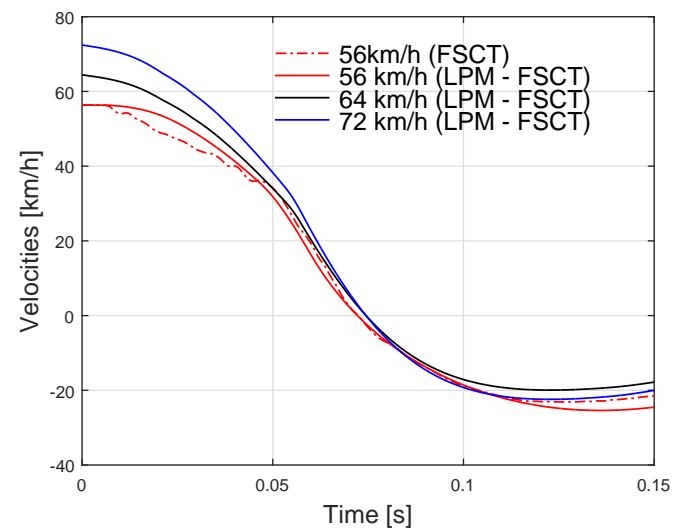

(d)

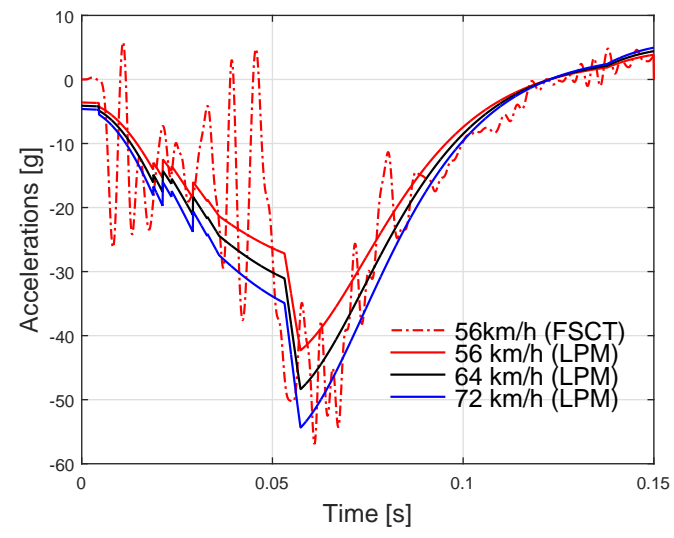

(f)

Figure 7. Displacement, velocity, and acceleration plots comparison in case of LPM calibrated to FSCT, (a,c,e) impact velocities lower than the calibration point $(56 \mathrm{~km} / \mathrm{h}) ;(\mathbf{b}, \mathbf{d}, \mathbf{f})$ impact velocities higher than the calibration point.

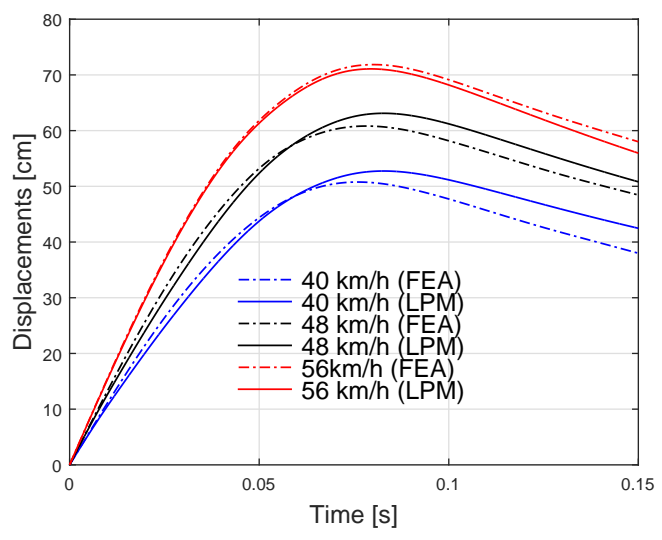

(a)

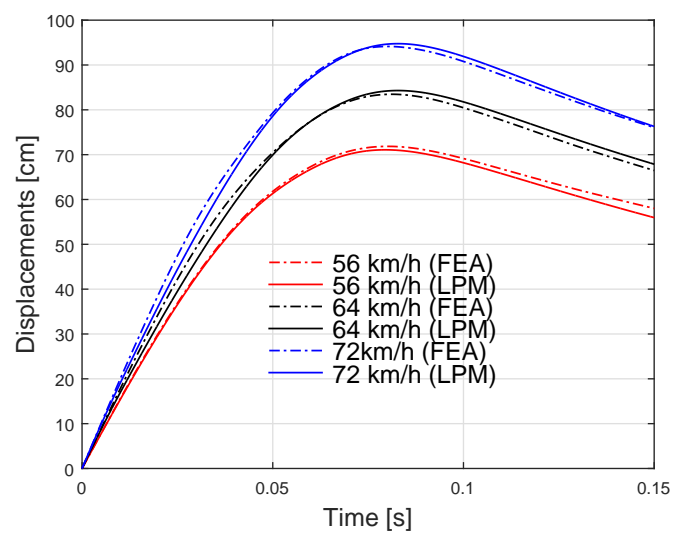

(b)

Figure 8. Cont. 


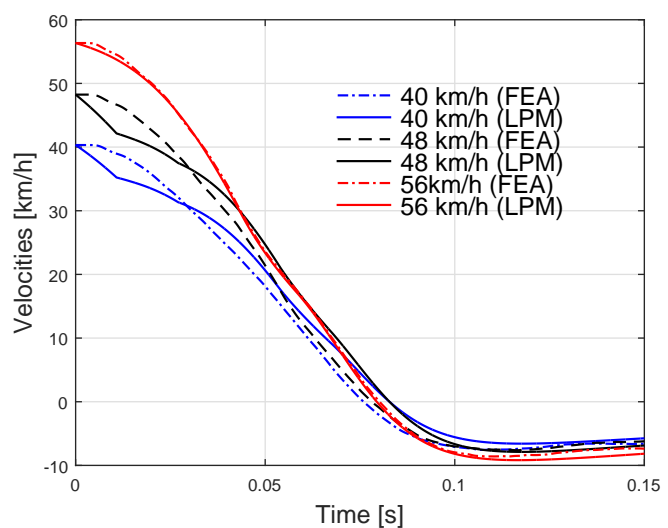

(c)

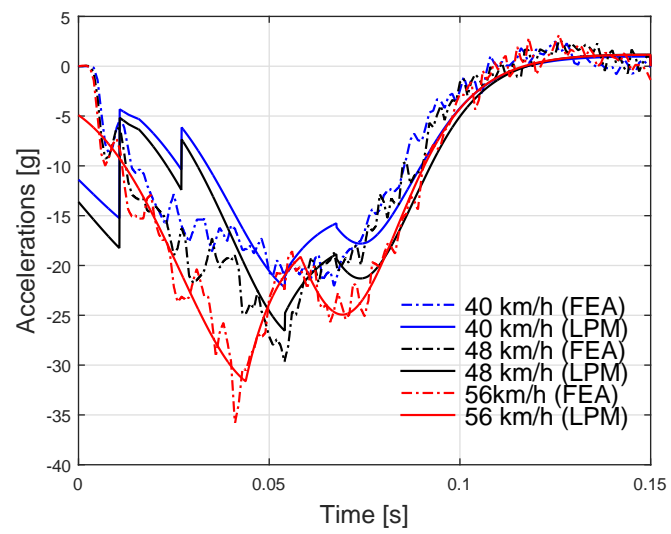

(e)

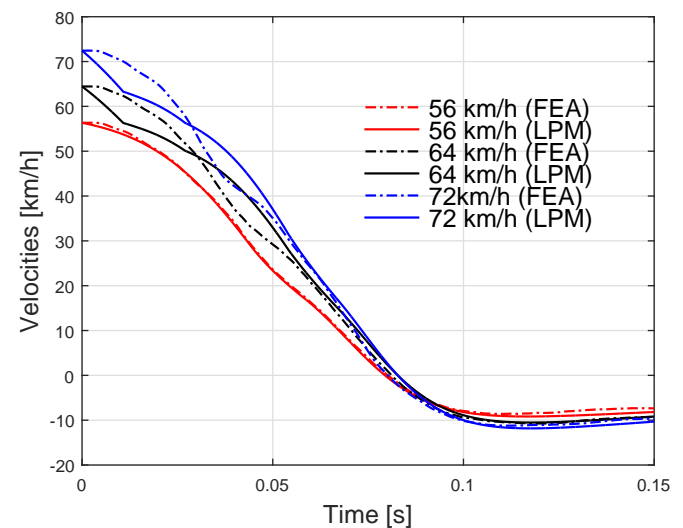

(d)

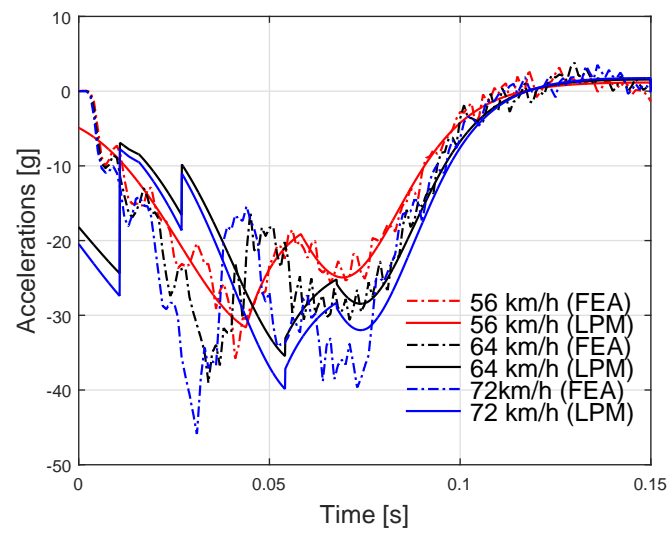

(f)

Figure 8. Displacement, velocity, and acceleration plots comparison in case of LPM calibrated to FEA, $(\mathbf{a}, \mathbf{c}, \mathbf{e})$ impact velocities lower than the calibration point $(56 \mathrm{~km} / \mathrm{h}) ;(\mathbf{b}, \mathbf{d}, \mathbf{f})$ impact velocities higher than the calibration point.

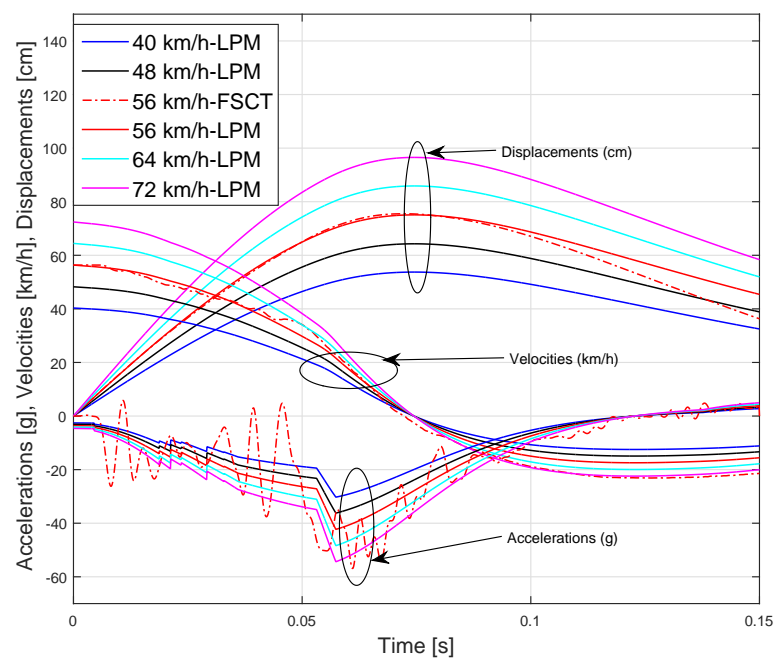

(a)

Figure 9. Cont. 


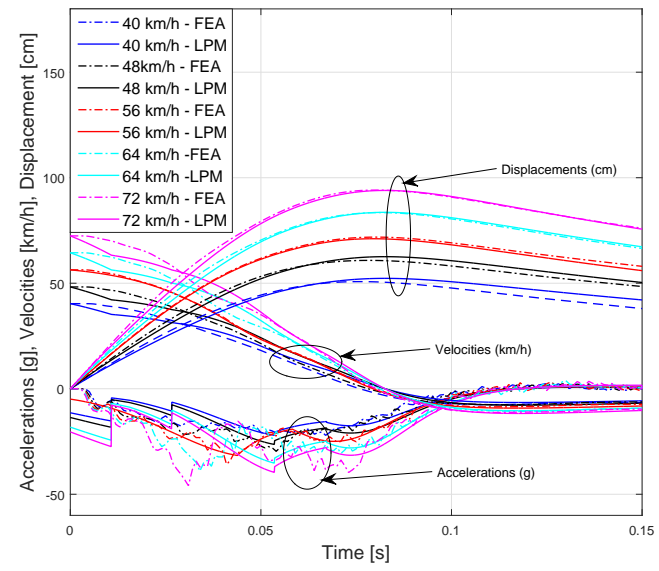

(b)

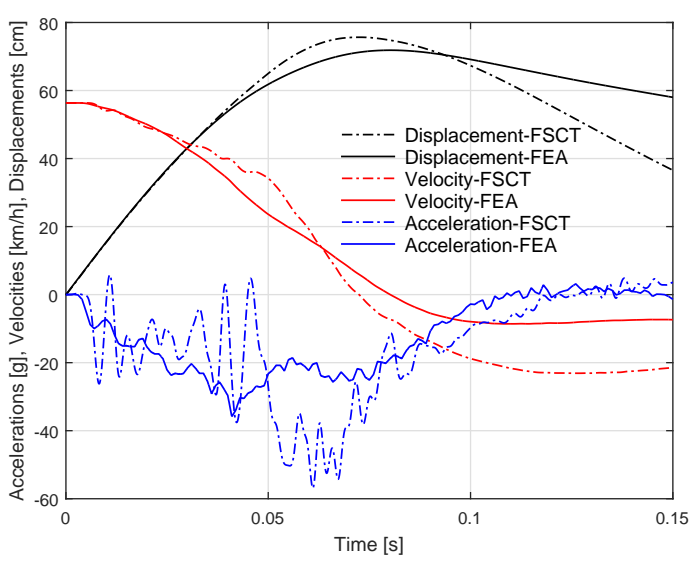

(c)

Figure 9. A summary of kinematic time histories for (a) LPM calibrated to FSCT; (b) LPM calibrated to FEM; (c) comparison between FEA and FSCT at $56 \mathrm{~km} / \mathrm{h}$.

\section{Discussion}

During the real vehicle crash event, the front structure of the car is deformed plastically and the amount of deformation is measured by the maximum dynamic crush. At maximum dynamic crush, the car stops when the velocity decreases up to zero and then increases negatively when the car gets separated from the barrier. In this study, the LPM simulates the crash event. This was achieved by first calibrating the model with acceleration signal from FSCT and FEM for a portion of deformation from the time of contact with the barrier up to time of maximum dynamic crush. From Table 1, it is observed that the estimated stiffness value increases at the maximum dynamic crush while, at the same time, the damping coefficient decreases. The kinematics results from the LPM match those from FSCT up to the maximum dynamic crush. From Table 2, it is shown that the maximum dynamic crashes from the FSCT and LPM are $0.7551 \mathrm{~m}$ and $0.7508 \mathrm{~m}$, respectively, and occur after $0.0723 \mathrm{~s}$ for FSCT and $0.0738 \mathrm{~s}$ for LPM. From Figure 7, a deviation is observed just after the time of maximum dynamic crush.

Table 2. Estimated crashworthiness parameters for FSCT, LPM and FEA.

\begin{tabular}{|c|c|c|c|c|c|c|}
\hline \multirow[b]{2}{*}{ Approaches } & \multicolumn{6}{|c|}{ Impact Velocities } \\
\hline & Parameters & $40 \mathrm{~km} / \mathrm{h}$ & $48 \mathrm{~km} / \mathrm{h}$ & $56 \mathrm{~km} / \mathrm{h}^{\mathrm{c}}$ & $64 \mathrm{~km} / \mathrm{h}$ & $72 \mathrm{~km} / \mathrm{h}$ \\
\hline \multirow{3}{*}{ FSCT } & $t_{m}[\mathrm{~s}]$ & - & - & 0.0723 & - & - \\
\hline & $C_{m}[\mathrm{~m}]$ & - & - & 0.7551 & - & - \\
\hline & ASI [-] & - & - & 2.5 & - & - \\
\hline \multirow{3}{*}{ LPM calibrated to FSCT } & $t_{m}[\mathrm{~s}]$ & 0.0736 & 0.0740 & 0.0738 & 0.0741 & 0.0741 \\
\hline & $C_{m}[\mathrm{~m}]$ & 0.5373 & 0.6429 & 0.7508 & 0.8588 & 0.9653 \\
\hline & ASI [-] & 1.7 & 2.1 & 2.6 & 2.7 & 3.1 \\
\hline \multirow{3}{*}{ FEA } & $t_{m}[\mathrm{~s}]$ & 0.0755 & 0.0781 & 0.0801 & 0.0804 & 0.0800 \\
\hline & $C_{m}[\mathrm{~m}]$ & 0.5077 & 0.6077 & 0.7180 & 0.8331 & 0.9408 \\
\hline & ASI [-] & 1.5 & 1.8 & 2.0 & 2.3 & 2.5 \\
\hline \multirow{3}{*}{ LPM calibrated to FEA } & $t_{m}[\mathrm{~s}]$ & 0.0824 & 0.0825 & 0.0793 & 0.0822 & 0.0805 \\
\hline & $C_{m}[\mathrm{~m}]$ & 0.5231 & 0.6258 & 0.7108 & 0.8360 & 0.9396 \\
\hline & ASI [-] & 1.4 & 1.6 & 2.0 & 2.3 & 2.5 \\
\hline
\end{tabular}

In case of FEM, the frontal structure of the model absorbs enough kinetic energy. From Figure 5, the hood and fender are bent and the bumper is deformed plastically at the highest velocity $(72 \mathrm{~km} / \mathrm{h})$. This is due to many elements that buckle together when the front structure is completely compressed 
at the maximum dynamic crush. When the LPM is calibrated to the FEM, a reasonable agreement between the results from LPM and those from FEA is observed as shown in Figure 8. It is shown that the maximum error between the maximum dynamic crush $C_{m}$, from the FEA and LPM is less than $3 \mathrm{~cm}$ for all impact velocities.

This is made evident by the dynamic crushes with their respective time of occurrence. It is noted from Table 2 that the maximum dynamic crush and the ASI for LPM and FEM are similar at a specific impact velocity. The results show that the ASI is high (greater than 1.9) when the impacting velocity of the vehicle is greater than $48 \mathrm{~km} / \mathrm{h}$.

The predictions show that a constant increment of $11 \mathrm{~cm}$ of the maximum dynamic crush is observed for a corresponding increment of $8 \mathrm{~km} / \mathrm{h}$ for the impact velocity when the LPM is calibrated to an FSCT. Likewise, an increment of $10 \mathrm{~cm}$ is observed on the maximum dynamic crush when the LPM is calibrated to an FEM. The high values of ASI reported in this work are due to the rigidity of the barrier. The results show that the LPM agrees with the experimental data obtained from the NHTSA, collected on a FORD TAURUS model crashing into a flat load cell barrier at $56 \mathrm{~km} / \mathrm{h}$ with Test No.5143, Curve No.122 [35] and the conventional FEA. The calibration time for the LPM is between 15 and $30 \mathrm{~min}$ and the simulation takes less than $20 \mathrm{~s}$, while the actual computational time for the FEA is between one and two days excluding the undefined time spent in developing the complex FEM of a complete vehicle.

\section{Conclusions and future work}

It is obvious that simple LPM cannot replace the complex FE model with regard to crash simulations, but it can assist with speeding up the analysis. Due to the complexity of the FEM, the analyst typically needs several iterations with adjustment of simulation parameters before a successful simulation is produced. In this work, three to five iterations were necessary, each taking about half of the full simulation time before the analysis termination. Hence, to produce a single successful $\mathrm{FE}$ analysis of the crash event required about a week of working time. To produce an $\mathrm{N}$ number of successful FE simulations for a range of velocities would typically take less time than $\mathrm{N}$ weeks since, once a successful combination of parameters is found, it can be used for most of the simulations and only minor adjustments are needed for different velocities. In the current study, the FE analysis for the five different velocities was produced within a month. Using an LPM allows for performing one FEA instead of five, calibrate the LPM to FEM and obtain the estimate of the crash parameters for a range of velocities. Hence, combining LPM and FEM extracts preliminary results of a month work within a week.

In future work, the integration of flexible barrier in LPM could be investigated. Other evolutionary-based algorithms such as the Differential Evolution (DE), Covariance Matrix Adaptation Evolution Strategy (CMA-ES), and Particle Swarm Optimization (PSO) could be tried for further improvement on the current results obtained using the GA. The extension of this work could be the consideration of the predictive capabilities of the LPM for other crash scenarios such as an oblique crash, side impact, and vehicle-to-vehicle crash, respectively. The expected challenges could be the representation of bending, of multi-dimensional/multi-axial deformations in other vehicle crash configurations. Other challenges expected when analysing the oblique and side crash with LPM could be the complexity in the extracting of parameters in case of a multi-dimension model.

Author Contributions: B.B.M. was the main author, proposed the approach, processed the data, analysed the results and wrote the article; D.V. and K.G.R. were the scientific advisers, supervised the work and revised the article; M.K. performed the FEA and the final revision of the article.

Funding: This research received no external funding.

Conflicts of Interest: The authors declare no conflict of interest. The research is part of the main author's $\mathrm{PhD}$-project and is funded by the University of Agder, Kristiansand and Grimstad, Norway. 


\section{References}

1. European Standard EN 1317-1. Road Restraint Systems Part 1, Terminology and General Criteria For Test Methods; Technical Report; European Committee of Standardization: Brussels, Belgium, 2010.

2. Pawlus, W.; Karimi, H.R.; Robbersmyr, K.G. Development of lumped-parameter mathematical models for a vehicle localized impact. J. Mech. Sci. Technol. 2011, 25, 1737-1747. [CrossRef]

3. Kamal, M. Analysis and Simulation of Vehicle to Barrier Impact. SAE Int. Tech. Paper 1970, 1-6. [CrossRef]

4. Marzbanrad, J.; Pahlavani, M. Calculation of vehicle-lumped model parameters considering occupant deceleration in frontal crash. Int. J. Crashworthiness 2011, 16, 439-455. [CrossRef]

5. Marler, R.T.; Kim, C.H.; Arora, J.S. System identification of simplified crash models using multi-objective optimization. Comput. Methods Appl. Mech. Eng. 2006, 195, 4383-4395. [CrossRef]

6. Kim, C.H.; Mijar, A.R.; Arora, J.S. Development of simplified models for design and optimization of automotive structures for crashworthiness. Struct. Multidiscip. Optim. 2001, 22, 307-321. [CrossRef]

7. Huang, M. Vehicle Crash Mechanics, 1st ed.; CRC PRESS: Boca Raton, FL, USA, 2002.

8. Pawlus, W.; Nielsen, J.E.; Karimi, H.R.; Robbersmyr, K.G. Application of viscoelastic hybrid models to vehicle crash simulation. Int. J. Crashworthiness 2011, 55, 369-378. [CrossRef]

9. Alnaqi, A.; Yigit, A. Dynamic Analysis and Control of Automotive Occupant Restraint Systems. Jordan J. Mech. Ind. Eng. 2011, 5, 39-46.

10. Klausen, A.; Tørdal, S.S.; Karimi, H.R.; Robbersmyr, K.G.; Jecmenica, M.; Melteig, O. Firefly Optimization and Mathematical Modeling of a Vehicle Crash Test Based on Single-Mass. J. Appl. Math. 2014, 1-10. [CrossRef]

11. Klausen, A.; Tørdal, S.S.; Karimi, H.R.; Robbersmy, K.G. Mathematical Modeling and Numerical Optimization of Three Vehicle Crashes using a Single-Mass Lumped Parameter Model. In Proceedings of the 24th International Technical Conference on the Enhanced Safety of Vehicles (ESV), Gothenburg, Sweden, 8-11 June 2015; pp. 44-49.

12. Ofochebe, S.M.; Ozoegwu, C.G.; Enibe, S.O. Performance evaluation of vehicle front structure in crash energy management using lumped mass spring system. Adv. Model. Simul. Eng. 2015, 2, 1-18. [CrossRef]

13. Munyazikwiy, B.B.; Karimi, H.R.; Robbersmyr, K.G. A Mathematical Model for Vehicle-Occupant Frontal Crash using Genetic Algorithm. In Proceedings of the 2016 UKSim-AMSS 18th International Conference on Computer Modelling and Simulation, Cambridge, UK, 6-8 April 2016.

14. Munyazikwiye, B.B.; Karimi, H.R.; Robbersmyr, K.G. Optimization of Vehicle-to-Vehicle Frontal Crash Model Based on Measured Data Using Genetic Algorithm. IEEE Access 2017, 5, 3131-3138. [CrossRef]

15. Pahlavani, M.; Marzbanrad, J. Crashworthiness study of a full vehicle-lumped model using parameters optimization. Int. J. Crashworthiness 2015, 20, 573-591. [CrossRef]

16. Lim, J.M. A Consideration on the Offset Frontal Impact Modeling Using Spring-Mass Model. Int. J. Mech. Aerosp. Ind. Mech. Manuf. Eng. 2015, 9, 1453-1458.

17. Lim, J.M. Lumped Mass-Spring Model Construction for Crash Analysis using Full Frontal Impact Test Data. Int. J. Automot. Technol. 2017, 18, 463-472. [CrossRef]

18. Mentzer, S.G. The SISAME-3D Program: Structural Crash Model Extraction And Simulation; Technical Report; US Department of Transportation: Washington, DC, USA, 2007.

19. Mentzer, S.; Radwan, R.; Hollowel, W. The SISAME methodology for extraction of optimal lumped parameter structural crash models. SAE Tech. Paper 1992. [CrossRef]

20. Gabler, H.C.; Hollowell, W.; Summers, S. Systems modeling of frontal crash compatibility. In Proceedings of the 2000 SAE International Congress and Exposition, Detroit, MI, USA, 13-15 January 2000; pp. 1-8.

21. Mazurkiewicz, L.; Baranowski, P.; Karimi, H.R.; Damaziak, K.; Malachowski, J.; Muszynski, A.; Muszynski, A.; Robbersmyr, K.G.; Vangi, D. Improved child-resistant system for better side impact protection. Int. J. Adv. Manuf. Technol. 2018, 97, 3925-3935. [CrossRef]

22. Vangi, D.; Cialdai, C.; Gulino, M.S.; Robbersmyr, K.G. Vehicle Accident Databases: Correctness Checks for Accident Kinematic Data. Designs 2018, 2, 1-11. [CrossRef]

23. Sousa, L.; Verssimo, P.; Ambrosio, J. Development of generic multibody road vehicle models for crashworthiness. Multibody Syst. Dyn. 2008, 19, 133-158. [CrossRef]

24. Teng, T.; Chang, F.; Liu, Y.; Peng, C. Analysis of dynamic response of vehicle occupant in frontal crash using multibody dynamics method. Math. Comput. Model. 2008, 48, 1724-1736. [CrossRef] 
25. Carvalho, M.; Ambrosio, J.; Eberhard, P. Identification of validated multibody vehicle models for crash analysis using a hybrid optimization procedure. Struct. Multidiscip. Optim. 2011, 44, 85-97. [CrossRef]

26. Carvalho, M.; Ambrósio, J. Identification of multibody vehicle models for crash analysis using an optimization methodology. Multibody Syst. Dyn. 2010, 24, 325-345. [CrossRef]

27. Ibrahim, H.K. Design Optimization of Vehicle Structures for Crashworthiness Improvement. Ph.D. Thesis, Concordia University, Montreal, QC, Canada, 2009.

28. Mahmood, H.F.; Fileta, B.B. Vehicle Crashworthiness and Occupant Protection; Chapter 2; American Iron and Steel Institute: Washington, DC, USA, 2004; pp. 20-21.

29. Deb, A.; Srinivas, K.C. Development of a new lumped-parameter model for vehicle side-impact safety simulation. J. Autom. Eng. 2008, 222, 1793-1811. [CrossRef]

30. Piyush Dube, M.L.J.; Suman, V.B. Lumped Parameter Model for Design of Crash Energy Absorption Tubes. MSRUAS-SAS Tech. J. 2014, 13, 5-7.

31. Ofochebe, S.; Enibe, S.; Ozoegwu, C. Absorbable energy monitoring scheme: new design protocol to test vehicle structural crashworthiness. Heliyon Elsevier 2016, 2, 1-33. [CrossRef] [PubMed]

32. Tanlak, N.; Sonmez, F.; Senaltun, M. Shape optimization of bumper beams under high-velocity impact loads. Eng. Struct. 2015, 95, 49-60. [CrossRef]

33. Lu, Q.; Karimi, H.R.; Robbersmyr, K.G. A Data-Based Approach for Modeling and Analysis of Vehicle Collision by LPV-ARMAX Models. J. Appl. Math. 2013, 2013, 1-10. [CrossRef]

34. Prasad, P.; Padgaonkar, A.J. Static-to-Dynamic Amplification Factors for Use in Lumped-Mass Vehicle Crash Models. Soc. Autom. Eng. 1981, 1-43. [CrossRef]

35. NHTSA. Vehicle Crash Test Database. 2016. Available online: http:/ / www-nrd.nhtsa.dot.gov/database/ vsr/veh/querytest.aspx (accessed on 25 May 2016).

36. NHTSA. LS-DYNA FE Crash Simulation Vehicle Models. Available online: https://www.nhtsa.gov/crashsimulation-vehicle-models (accessed on 15 June 2016).

37. Livermore Software Technology Corporation, Livermore, California 94551-0712. LS-DYNA Keyword User's Manual, VOLUME II, Ls-Dyna R9.0 ed. 2016. Available online: https:/ / www.dynamore.de/de/download/ manuals/ls-dyna/ls-dyna-manual-r-9.0-vol-ii-16-mb (accessed on 24 October 2018).

38. LSDYNA Supports. Available online: https://www.dynasupport.com/howtos/element/hourglass (accessed on 29 May 2018).

39. European Standard EN 1317-2. Road Restraint Systems Part 2, Performance Classes, Impact Test Acceptance Criteria and Test Method for Safety Barriers Including Vehicle Parapets; Technical Report; European Committee of Standardization: Brussels, Belgium, 2010.

40. Shojaat, M. Correlation between injury risk and impact severity index ASI. In Proceedings of the Swiss Transport Research Conference, Monte Verità/Ascona, Sweden, 20-22 March 2003. 